\title{
AVALIAÇÃO DO POTENCIAL INSETICIDA DO ÓLEO ESSENCIAL DE CITRUS PARADISI NO CONTROLE DOS ESTÁGIOS IMATUROS E ADULTOS DE CTENOCEPHALIDES FELIS
}

\author{
(Insecticide potential evaluation of Citrus paradisi essential oil in the control of Ctenocephalides felis felis \\ immature and adult stages)
}

Emily Andressa Santos Lima, Cecília Lopes da Conceição, Isabela Scalioni Gijsen, Jéssica Karoline de Oliveira Chaves, Diefrey Ribeiro Campos, Thais Paes Ferreira, Melina Cardilo Campos Alves, Katherina Comendouros

Universidade Federal Rural do Rio de Janeiro - UFRRJ, Rio de Janeiro, Brasil.

*Correspondência: emily.andressalima@gmail.com

RESUMO: A pulga Ctenocephalides felis (Siphonaptera: Pulicidae) é um inseto parasito de cães e gatos com distribuição cosmopolita. São insetos ápteros, pequenos, de coloração castanhoavermelhada e comportamento hematófago na fase adulta, onde o aparelho sugador é introduzido na epiderme, podendo causar irritação de pele, espoliação sanguínea e reações alérgicas. Possui importância na saúde pública por ser vetor de diversos agentes patogênicos à animais e ao homem. Citrus paradisi (Rutaceae) conhecido popularmente como Toranja. Pode possuir na composição de seu óleo essencial (OE) limoneno, mirceno, $\alpha$-pineno, $\beta$-pineno, $\beta$ cariofileno e cetona sesquiterpênica nootkatone que é responsável pelo seu aroma, o qual possui ação inseticida e repelente. Este trabalho teve por objetivo avaliar a atividade pulicida OE de Ci. paradisi frente aos estádios de ovo, larva, pupa e adulto da pulga C. felis. As pulgas em diferentes estádios utilizadas foram oriundas da colônia laboratorial de $C$. felis aprovado pelo Comissão de Ética no Uso de Animais com número de protocolo 4313110419. Para a realização dos testes in vitro foi preparada solução-mãe à $40000 \mu \mathrm{g} / \mathrm{mL}$ do OE de Ci. paradisi. Posteriormente, as soluções foram diluídas em acetona $20 \%$ de forma seriada (1:2). Para a avaliação da atividade adulticida, tiras de papel filtro whatman $(80 \mathrm{~g}) \mathrm{com} 10 \mathrm{~cm}^{2}$ foram impregnadas com $0,2 \mathrm{~mL}$ de cada solução. Para os estágios imaturos, discos do mesmo papel filtro com área $23.76 \mathrm{~cm}^{2}$ foram impregnados com $0.470 \mathrm{~mL}$ de cada solução. As concentrações obtidas por área foram de: 1,$5 ; 3,1 ; 6,2 ; 12,5 ; 25,0$; 50,$0 ; 100,0 ; 200,0 ; 400,0$ e $800,0 \mu \mathrm{g} / \mathrm{cm}^{2}$. Como controle foram utilizados papeis filtros impregnados com o mesmo volume com acetona $20 \%$. Para cada concentração foram utilizadas duas repetições. Para a avaliação da eficácia in vitro do óleo essencial de Ci. paradisi foram utilizados dez exemplares para cada fase do estádio. A avaliação da mortalidade foi realizada após 24 horas para os estádios de larva e adulto, após 72 horas para o estádio de ovo e após 15 dias para o estádio de pupa. Para os estádios de adulto e larva foram considerados como morte, indivíduos que não apresentassem motilidade. Já para o estádio de ovo, foram considerados mortos os exemplares que não eclodiram e para o estádio de pupa, foram considerados mortas as pupas que não emergiram como pulgas adultas. A mortalidade observada para a concentração de $800,0 \mathrm{\mu g} / \mathrm{cm}^{2}$, para os diferentes tempos de exposição a OE de Ci. paradisi, foi, 0, 15, 0 e 5\% para o estádio de ovo, larva, pupa e adulto, respectivamente. Com base nos resultados obtidos neste estudo conclui-se que $\mathrm{O} \mathrm{OE}$ de $\mathrm{Ci}$. paradisi não apresentou atividade inseticida frente aos diferentes estádios de $C$. felis.

Palavras-chave: atividade pulicida; grapefruit; pulga do gato.

\section{Nota}

Trabalho aprovado pelo comitê de ética (CEUA/IV) da universidade federal rural do rio de janeiro sob o número 4313110419. 